\title{
Calibration of resistance factors for drilled shafts considering lower-bound resistance
}

\author{
Seok-Jung Kim ${ }^{\text {i) }}$, Jae-Hyun Park ${ }^{\text {ii) }}$ and Myoung-Mo Kim ${ }^{\text {iii) }}$ \\ i) Assistant Manager, Technology R\&D Institute, Soosung Engineering Co., Ltd., Korea \\ ii) Research fellow, Geotechnical Engineering Research Div. Korea Institute of Civil Engineering and Building Technology, Korea \\ iii) Honorary Faculty, Dept. of Civil \& Environmental Engineering, Seoul National University, Korea
}

\begin{abstract}
The Load Resistance Factor Design (LRFD) was introduced in Korea about a decade ago. However, the resistance factors suggested by AASHTO $(2007,2010)$ represent the characteristics of bedrocks in the US that may differ from those in Korea. There is also a general belief that the calculated probabilities of failure from conventional reliability analyses are not realistic because of the conservative bias used when predicting resistance and tails of probability distributions for load and resistance. The existence of a lower bound of resistance affects the reliability and resistance factors even though the lower bound of resistance is small. Thus, it is important to determine accurate resistance factors for drilled shafts based on reliable load test results and to calibrate the resistance factors considering lower-bound resistance.

In this paper, an accurate resistance factor for drilled shafts was determined based on 13 sets of drilled shaft bi-directional load test data with strain gauges. Using a new log-normal distribution with lower bound of resistance, reliability analysis and resistance factor was performed using the advanced first order second moment (AFOSM) method. The target reliability indices were determined as 2.5, 3.0, and 3.5. For the target reliability index of 3.0 (AASHTO recommended value), the resistance factors were determined in the range of $0.13-0.32 \mathrm{for}$ shaft resistance, 0.19-0.29 for base resistance.

The lower bounds of resistance for each resistance (shaft and base) were determined, to be applied in the various bearing capacity equations, based on the Hoek-Brown failure criteria (2002) and the downgraded GSI values. Considering the lower-bound resistance, resistance factors were increased by up to $8 \%$ for the shaft resistance factor and $13 \%$ for the base resistance factor.
\end{abstract}

Keywords: Load Resistance Factor Design (LRFD), drilled shaft, resistance factor, lower-bound resistance

\section{INTRODUCTION}

Recently, the Load Resistance Factor Design (LRFD) has been substituted for the Allowable Stress Design (ASD) or Working Stress Design (WSD), for the design of foundations around the world. The Load Resistance Factor Design (LRFD) method was introduced into Korea about a decade ago. The LRFD method considers the uncertainty of the resistance, based on reliability analysis. Therefore, the probability of failure can be quantitatively estimated. Consequently, consistent and reliable designs of geotechnical structures are possible. However, to ensure coherent reliability, representative resistance and load factors should be estimated. AASHTO $(2007,2010)$ suggested resistance factors for the design of a drilled shaft socketed in bedrock as $0.50 \sim 0.55$ for the shaft resistance, and 0.50 for the base resistance.

However, the resistance factors suggested by AASHTO (2010) should represent the characteristics of bedrocks defined in the US, which may differ from the bedrocks in Korea. The resistance factors suggested by AASHTO (2010) are determined only for the intact rock condition. In contrast, in the case of bedrocks in Korea, the representative rock types are granite and gneiss; and these rocks are classified by the strength criteria as moderate or hard rock. However, there are many discontinuities and much weathering, so rocks are classified by the weathering degree criteria as weathered rock or soft rock. Therefore, there are discrepancies in the rock conditions between the US and Korea, and the direct application of the AASHTO resistance factors for domestic design is not appropriate.

Also, there is a general belief that the calculated probabilities of failure from conventional reliability analysis are not realistic, because of the conservative bias used when predicting resistance and tails of probability distributions for the load and resistance. A general log-normal distribution of resistance, with a lower tail that extends to zero, does not capture the 
realistic possibility. There is a physical limit to the smallest possible capacity for a pile foundation. This limit is greater than zero, and is defined as the lower bound for the resistance.

Previous researches by Najjar (2005) investigated the possibility of a lower bound capacity for driven steel pipe piles in cohesive and cohesionless soils, and indicated strong evidence for the existence of a lower bound capacity. In geotechnical engineering applications, the left-hand tail of the resistance distribution governs the probability of failure. As a result, the existence of a lower bound of resistance affects the reliability and resistance factors, even though the lower bound of the resistance is small. So, Najjar (2005) suggested the mixed probability distribution for modeling the resistance shown in Fig. 1, and used this probability distribution for calibration of resistance factors. Therefore, it is necessary to calibrate the resistance factors considering the lower-bound resistance.

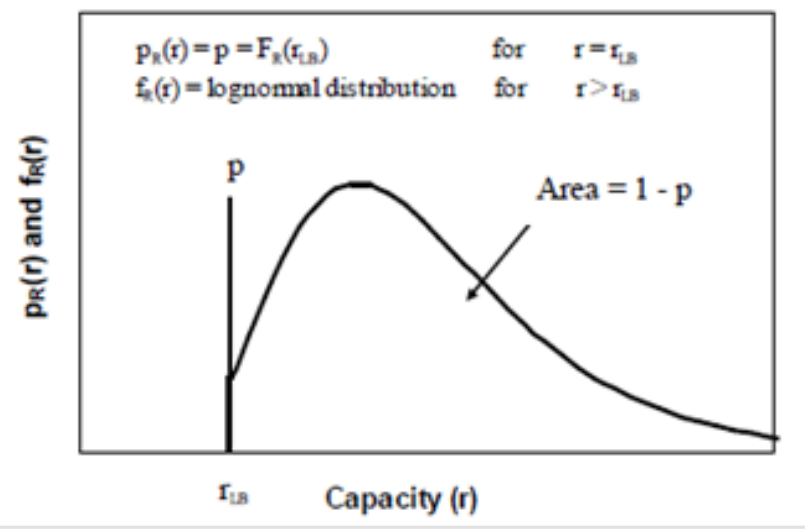

Fig. 1. Mixed probability distribution for modeling the resistance (Najjar, 2005)

The main purposes of this study are to

1) determine accurate resistance factors for drilled shafts, based on the reliable load test results, and

2) calibrate the determined resistance factors, considering lower-bound resistance.

For this study, 13 sets of load test results were collected and analyzed to determine the resistance factors. After then, lower-bound resistances were calculated based on Hoek-Brown failure criteria and GSI downgrading, and resistance factor were calibrated considering lower-bound resistance.

\section{LOAD TEST}

\subsection{Collected load test data}

For this study, 13 sets of drilled shaft load test results with strain gauges were collected.

In procedure for reliability-based resistance factor calibration, the measured resistance can influence the results of reliability analysis and resistance factor determination significantly. Therefore, it is very important to measure the accurate resistance for determination of resistance factor. In this study, load transfer analyses were performed based on the measured strain from strain gauge and more accurate shaft and base resistances were measure. The test pile profile and site investigation results are summarized in Table 1.

Table 1. Test pile profile and site investigation results

\begin{tabular}{llllll} 
No. & $\begin{array}{l}\text { Embedded } \\
\text { depth(m) }\end{array}$ & Rock & D (m) & $\begin{array}{l}\text { Load } \\
\text { (ton) }\end{array}$ & UCS(MPa) \\
\hline TP 1 & 38.96 & WR + SR & 2.35 & 10,750 & $3.1 \sim 19.8$ \\
\hline TP 2 & 36.21 & WR + SR & 1.85 & 5,000 & $10.2 \sim 25.4$ \\
\hline TP 3 & 33.41 & WR + SR & 1.35 & 4,500 & $5.6 \sim 25.0$ \\
\hline TP 4 & 36.38 & WR + SR & 1.85 & 3,750 & $1.8 \sim 8.7$ \\
\hline TP 5 & 55.42 & WR + SR & 3.0 & 21,000 & $30.4 \sim 194$ \\
\hline TP 6 & 56.60 & WR & 2.4 & 17,000 & $5 \sim 14$ \\
\hline TP 7 & 51.20 & WR + SR & 2.4 & 12,000 & $44 \sim 47$ \\
\hline TP 8 & 52.26 & WR + SR & 2.4 & 9,000 & $1 \sim 192$ \\
\hline TP 9 & 33.50 & WR & 1.5 & 1,950 & $71.4 \sim 87.2$ \\
\hline TP 10 & 13.50 & WR & 1.0 & 1,800 & 38 \\
\hline TP 11 & 13.50 & WR & 1.0 & 1,800 & 38 \\
\hline TP 12 & 13.50 & WR & 1.0 & 1,800 & 38 \\
\hline TP 13 & 13.50 & WR & 1.0 & 1,800 & 38 \\
\hline
\end{tabular}

* WR: Weathered Rock, SR: Soft Rock, D: Diameter, UCS: Unconfined Compressive Strength

Most of the piles were socketed into soft rock or weathered rock. Unconfined strengths of bedrock were estimated from point load test and unconfined compressive load test. Also, strain gauges were installed in each test piles to evaluate shaft and base resistance using load transfer analysis. The test piles of TP 1 to TP 8 were instrumented with strain gauges to load transfer mechanisms. However, the piles of TP 9 to TP 13 were not installed with strain gauges, thus load transfer analysis was not conducted.

\subsection{Analysis of load test results}

Shaft resistances and base resistances are determined through load transfer analysis using measured strain data. In this study, calibration of elastic modulus is performed to determine the more accurate and realistic resistances.

In general cases of load transfer analysis, constant elastic modulus $\left(E_{50}\right)$ of drilled shafts has been commonly used. However, according to Fellenius (1989), elastic modulus of concrete shows nonlinear stress-strain characteristic when concrete piles were loaded. As shown in Fig. 2, the tangent modulus of the concrete pile is not constant but reducing and the line slopes downward with increasing strain. Therefore, calibrated elastic moduli of test piles were applied to load transfer analysis for more accurate resistance. The example of calibrated elastic modulus of TP1 is shown in Fig. 3. 


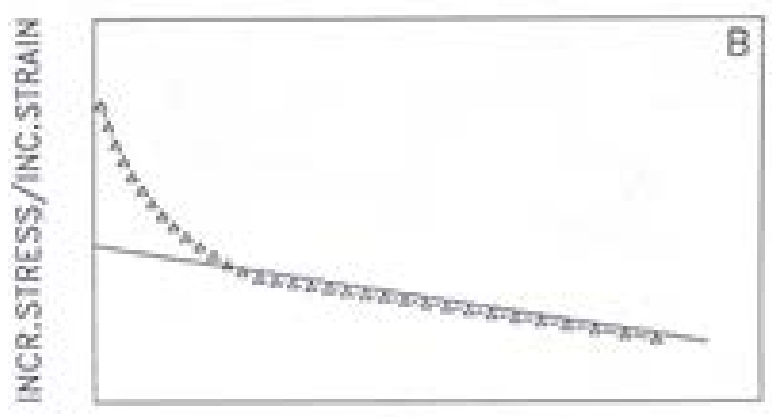

S T R A I N

Fig. 2. Elastic modulus reducing with increasing stress (Fellenius, 1989)

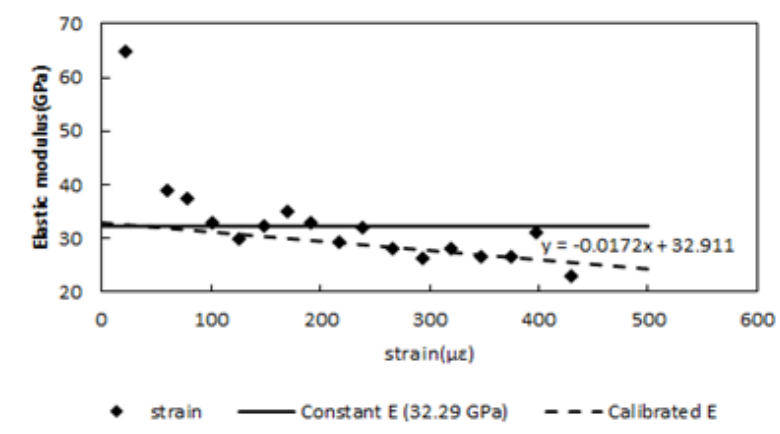

Fig. 3. Calibrated elastic modulus of TP 1

\section{DETERMINATION OF RESISTANCE FACTORS}

\subsection{Measured resistance}

Load transfer analysis was performed to measure shaft and base resistances based on the pile load test results. Axial loads at each depth were calculated using the strain gage data, and the unit shaft resistance-displacement curves (f-w curve) for each depth and unit base resistance-displacement curves (q-w curve) at base of drilled shafts were then established using the calculated axial loads. There are some criteria for determining the ultimate shaft and base resistance from $\mathrm{f}-\mathrm{w}$ curve and $\mathrm{q}-\mathrm{w}$ curve. In this study, the ultimate shaft and base resistance is defined using O’Neill \& Reese (1999) research. According to research by O’Neill \& Reese (1999), ultimate shaft resistance is determined when the displacement of the pile is equal to $1 \%$ of the pile diameter, and ultimate base resistance is determined when the displacement of the pile is equal to $5 \%$ of the pile diameter. Thus, measured shaft and base resistance were determined when the displacement of the pile was reached to each displacement based on the f-w curve and q-w curve. If load tests were terminated when the displacements were not reached to each criteria, $\mathrm{f}-\mathrm{w}$ curves and $\mathrm{q}-\mathrm{w}$ curves were plotted and extrapolated by hyperbolic methods.

\subsection{Predicted resistance}

Predicted resistances are necessary to calibrate the resistance factors, and determination of representative predicted resistance is important. With measured resistances from load test data, predicted resistances are used for evaluating of pile resistance uncertainty. In this study, predicted resistances were calculated by bearing capacity equation using unconfined compressive strength of rock core. Selected bearing capacity equations are summarized in Table 2.

Table 2. Test pile profile and site investigation results

\begin{tabular}{|c|c|c|}
\hline $\begin{array}{l}\text { Resistance } \\
\text { component }\end{array}$ & Design method & Bearing capacity equation \\
\hline \multirow{4}{*}{$\begin{array}{l}\text { Shaft } \\
\text { Resistance }\end{array}$} & $\begin{array}{l}\text { Carter \& Kulhawy } \\
\text { (1988) }\end{array}$ & $\mathrm{f}_{\mathrm{s}}=6.47 \sqrt{\mathrm{qu}_{\mathrm{u}}}(\mathrm{kPa})$ \\
\hline & $\begin{array}{l}\text { Horvath \& Kenney } \\
\text { (1979) }\end{array}$ & $\mathrm{f}_{\mathrm{s}}=6.88 \sqrt{\mathrm{qu}_{\mathrm{u}}}(\mathrm{kPa})$ \\
\hline & $\begin{array}{l}\text { FHWA } \\
(1999)\end{array}$ & $\mathrm{f}_{\mathrm{s}}=0.65 \times \mathrm{p}_{\mathrm{a}}\left[\mathrm{q}_{\mathrm{u}} / \mathrm{p}_{\mathrm{a}}\right]^{0.5}(\mathrm{kPa})$ \\
\hline & $\begin{array}{l}\text { Rowe \& Armitage } \\
\text { (1987) }\end{array}$ & $\mathrm{f}_{\mathrm{s}}=14.89 \sqrt{\mathrm{qu}_{\mathrm{u}}}(\mathrm{kPa})$ \\
\hline \multirow{3}{*}{$\begin{array}{l}\text { Base } \\
\text { Resistance }\end{array}$} & $\begin{array}{l}\text { Carter \& Kulhawy } \\
\text { (1988) }\end{array}$ & $\begin{array}{l}\mathrm{q}_{b} \\
=\left[\mathrm{s}^{0.5}+\left(\mathrm{m} \cdot \mathrm{s}^{0.5}+\mathrm{s}\right)^{0.5}\right] \mathrm{q}_{\mathrm{u}}(\mathrm{MPa})\end{array}$ \\
\hline & FHWA(1999) & $\mathrm{q}_{\mathrm{b}}=3 \mathrm{~K}_{\mathrm{sp}} \theta \mathrm{q}_{\mathrm{u}}(\mathrm{MPa})$ \\
\hline & $\begin{array}{l}\text { Zhang \& Einstein } \\
\text { (1998) }\end{array}$ & $\mathrm{q}_{\mathrm{b}}=4.83 q_{u}^{0.51}(\mathrm{MPa})$ \\
\hline
\end{tabular}

${ }^{*} \mathrm{q}_{\mathrm{u}}$ : UCS of rock core $(\mathrm{kPa}), \mathrm{p}_{\mathrm{a}}$ : atmospheric pressure $(101 \mathrm{kP} a)$, $\mathrm{m}, \mathrm{s}$ : mass properties, $\mathrm{K}_{\mathrm{sp}}$ : Emperical factor, $\theta$ : Depth factor

\subsection{Statistics of load and resistance}

To perform the reliability analysis for determination of resistance factors, load information in terms of statistics of load bias factors and resistance information in terms of statistics of resistance bias factors. Contrary to resistance statistics, load statistics are known that regional variations are negligible, therefore, load statistical characteristics and load factors from the current AASHTO LRFD Specifications (2010) were used in this study. The used load factors and load statistical parameters are summarized in Table 3.

Table 3. Statistics of load (AASHTO, 2010)

\begin{tabular}{llll}
\hline \multicolumn{2}{l}{ Load Factor of Dead Load $\left(\gamma_{\mathrm{D}}=1.25\right)$} & \multicolumn{2}{l}{ Load Factor of Live Load $\left(\gamma_{\mathrm{L}}=1.75\right)$} \\
\hline Bias factor & Coefficient of & Bias factor & Coefficient of \\
$\left(\lambda_{\mathrm{D}}\right)$ & Variation $\left(\delta_{\mathrm{D}}\right)$ & $\left(\lambda_{\mathrm{L}}\right)$ & Variation $\left(\delta_{\mathrm{L}}\right)$ \\
\hline 1.05 & 0.10 & 1.05 & 0.10 \\
\hline
\end{tabular}

Statistical characteristics of resistance are represented in terms of the bias factor, which is evaluated using the predicted resistance and measured resistances and defined as the ratio of the measured to predicted resistance. Determined resistance statistical characteristics are summarized in Table 4.

Table 4. Statistics of resistances

\begin{tabular}{llll}
\hline $\begin{array}{l}\text { Resistance } \\
\text { component }\end{array}$ & Design method & Bias factor $\left(\lambda_{\mathrm{R}}\right)$ & $\begin{array}{l}\text { Coefficient of } \\
\text { Variation }\left(\mathrm{COV}_{\mathrm{R}}\right)\end{array}$ \\
\hline \multirow{3}{*}{$\begin{array}{l}\text { Shaft } \\
\text { Resistance }\end{array}$} & Carter \& Kulhawy(1988) & 1.80 & 0.65 \\
\cline { 2 - 4 } & Horvath \& Kenney(1979) & 1.70 & 0.65 \\
\cline { 2 - 4 } & FHWA(1999) & 1.79 & 0.65 \\
\cline { 2 - 4 } $\begin{array}{l}\text { Base } \\
\text { Resistance }\end{array}$ & Carter \& Kulhawy(1988) & 1.30 & 0.65 \\
\cline { 2 - 4 } & FHWA(1999) & 1.12 & 0.64 \\
\cline { 2 - 4 } & Zhang \& Einstein(1998) & 0.97 & 0.67 \\
\hline
\end{tabular}




\subsection{Determination of target reliability index and resistance factor}

To consider a transition period from Allowable Stress Design (ASD) to Load Resistance Factor Design (LRFD), reliability analysis was performed and reliability index of the current design practice, ASD, were estimated. The Korean design standard for foundation structures requires a safety factor of 3.0 for pile bearing capacity design, and the range of factor of safety ranged from 2.0 to 3.0 which were generally practiced in construction. Therefore, reliability analysis was performed for factor of safety from 2.0 to 5.0 using AFOSM methods. The results of reliability analysis are summarized in Table 5.

Table 5. Reliability analysis results for target reliability index.

\begin{tabular}{llllll}
\hline \multirow{2}{*}{$\begin{array}{l}\text { Resistance } \\
\text { component }\end{array}$} & Design method & \multicolumn{4}{l}{ Reliability index (for each F.S) } \\
\cline { 2 - 6 } & 2.0 & 3.0 & 4.0 & 5.0 \\
\hline \multirow{3}{*}{$\begin{array}{l}\text { Shaft } \\
\text { Resistance }\end{array}$} & Carter \& Kulhawy(1988) & 1.73 & 2.40 & 2.88 & 3.25 \\
\cline { 2 - 6 } & Horvath \& Kenney(1979) & 1.62 & 2.30 & 2.78 & 3.15 \\
\cline { 2 - 6 } & FHWA(1999) & 1.71 & 2.39 & 2.87 & 3.24 \\
\hline \multirow{2}{*}{$\begin{array}{l}\text { Base } \\
\text { Resistance }\end{array}$} & Cawe \& Armitage(1987) & 0.34 & 1.01 & 1.49 & 1.86 \\
\cline { 2 - 6 } & FHWA(1999) & 0.89 & 1.41 & 2.02 & 2.38 \\
\cline { 2 - 6 } & Zhang \& Einstein(1998) & 1.08 & 1.97 & 2.60 & 3.08 \\
\hline
\end{tabular}

Also, the target reliability indices ranged from 2.5 to 3.7 suggested by previous researchers. Thus, the target reliability index of 2.5, 3.0 and 3.5 were selected for the calibration of resistance factors in this study.

After determination of the target reliability index, resistance factors were determined for each target reliability index and bearing capacity equation using AFOSM methods. Determined resistance factors were summarized in Table 6.

Table 6. Determined resistance factor

\begin{tabular}{lllll}
\hline \multirow{2}{*}{$\begin{array}{l}\text { Resistance } \\
\text { component }\end{array}$} & Design method & \multicolumn{3}{l}{ Resistance factor } \\
\cline { 3 - 5 } & $\beta_{\mathrm{T}}=2.5$ & $\beta_{\mathrm{T}}=3.0$ & $\beta_{\mathrm{T}}=3.5$ \\
\hline \multirow{3}{*}{$\begin{array}{l}\text { Shaft } \\
\text { Resistance }\end{array}$} & Carter \& Kulhawy(1988) & 0.45 & 0.32 & 0.24 \\
\cline { 2 - 5 } & Horvath \& Kenney(1979) & 0.42 & 0.30 & 0.22 \\
\cline { 2 - 5 } & FHWA(1999) & 0.44 & 0.32 & 0.24 \\
\cline { 2 - 5 } Base & Rowe \& Armitage(1987) & 0.19 & 0.13 & 0.11 \\
\cline { 2 - 5 } Resistance & FHWA(1999) & 0.25 & 0.19 & 0.17 \\
\cline { 2 - 5 } & Zhang \& Einstein(1998) & 0.37 & 0.29 & 0.24 \\
\hline
\end{tabular}

Consequently, for the target reliability index of 3.0 (AASHTO recommended value), resistance factors were determined in the range of $0.13-0.32$ for shaft resistance, 0.19-0.29 for base resistance.

\section{CALIBRATION OF RESISTANCE FACTOR CONSIDERING LOWER-BOUND RESISTANCE}

Resistance factors summarized in Table 6 are resistance factors which do not consider the lower-bound resistance. In other words, these resistance factors are resultant values when the lower-bound resistance equal to zero. However, there is generally a physical limit to the smallest possible capacity for a deep foundation capacity which is greater than zero, because that even highly disturbed soil generally has finite shear strength. So, there is a general belief that calculated probabilities of failure from conventional reliability analysis are not realistic due to conservative bias used to predicted resistance and tails of probability distribution. Therefore, lower-bound of resistance for drilled shafts were estimated and resistance factors were calibrated using lower-bound resistance.

According to Najjar (2005), design checking equation is defined as (1).

$$
\phi_{\mathrm{R}(\mathrm{LB})} \cdot \mathrm{r}_{\text {nominal }} \geq \gamma_{\mathrm{s}} \cdot \mathrm{s}_{\text {nominal }}
$$

where, $\phi_{R(L B)}$ indicate the resistance factor expressed as the function of the lower-bound capacity, $r_{\text {nominal }}$ is nominal resistance calculated using a design method, $\phi_{\mathrm{R}}$ is resistance factor, $s_{\text {nominal }}$ is nominal load for design, and $\gamma_{s}$ is load factor. When there is no lower bound and when the load and the resistance follow conventional lognormal distributions, the reliability and resistance factor are calculated from (2).

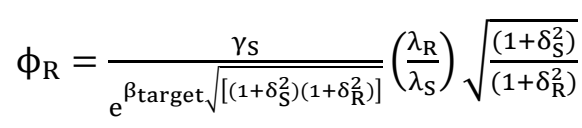

For a nonzero lower-bound capacity, the required factor of safety will decrease as the lower bound increases, and the required resistance factor when there is a lower-bound resistance, $\phi_{R(L B)}$, can be expressed in terms of the conventional case as (3).

$$
\phi_{\mathrm{R}(\mathrm{LB})}=\left(\frac{\mathrm{FS}_{(\mathrm{LB}=0)}}{\mathrm{FS}_{(\mathrm{LB})}}\right) \phi_{\mathrm{R}}
$$

\subsection{Estimation of lower-bound resistance}

\subsubsection{Lower-bound of shaft resistance}

Predicted resistances were calculated by bearing capacity equations using unconfined compressive strength of rock core shown as Table 2. However, unconfined compressive strengths of rock core are the value of intact rock. Considering that there are many discontinuities and weathering in bedrock in Korea, it is not appropriate to describe realistic bedrock condition and simulate the critical state of bedrock. Therefore, Hoek-Brown failure criteria (2002) were adopted to calculate the unconfined compressive strength of rock mass, and unconfined compressive strength of rock mass were applied into bearing capacity equations to estimate lower-bound of shaft resistance. Hoek et al. (2002) proposed the concept of a global rock mass strength for weathered rock mass as from (4) to (7).

$$
\mathrm{q}_{\mathrm{u}, \text { mass }}=\mathrm{q}_{\mathrm{u}, \text { core }} \times \frac{\left(\mathrm{m}_{\mathrm{b}}+4 \mathrm{~s}-\mathrm{a}\left(\mathrm{m}_{\mathrm{b}}-8 \mathrm{~s}\right)\right)\left(\frac{\mathrm{m}_{\mathrm{b}}}{4}+\mathrm{s}\right)^{\mathrm{a}-1}}{2(1+\mathrm{a})(2+\mathrm{a})}
$$




$$
\begin{gathered}
\mathrm{m}_{\mathrm{b}}=\mathrm{m}_{\mathrm{i}} \exp \left(\frac{\mathrm{GSI}-100}{28}\right) \\
\mathrm{s}=\exp \left(\frac{\mathrm{GSI}-100}{9}\right) \\
\mathrm{a}=\frac{1}{2}+\frac{1}{6}\left(\mathrm{e}^{-\mathrm{GSI} / 15}-\mathrm{e}^{-20 / 3}\right)
\end{gathered}
$$

Here, $m_{b}$ is a reduced value of the material constant $m_{i}$ (28 is recommended for gneiss which is the main rock type in Korea.), s and a are constants for the rock mass. Also, GSI is a geological strength index.

Also, the concept of lower-bound is physical limit to the smallest possible capacity for a deep foundation. Considering this concept, GSI for each bearing capacity equations were downgraded much as 10 points lower corresponding to one-category downgrading of rock structure in addition to rock mass strength.

\subsubsection{Lower-bound of base resistance}

Unlike the case of lower-bound of shaft resistance, predicted base resistances were calculated by bearing capacity equations using unconfined compressive strength of rock core and mass properties (m, s for Carter \& Kulhawy and $\mathrm{K}_{\mathrm{sp}}, \theta$ for FHWA) shown as Table 2. Therefore, other considerations were adopted for lower-bound of base resistance.

In case of Carter and Kulhawy (1988), the GSI values were downgraded much as 10 points lower to avoid the danger of duplication of Hoek-Brown (2002) failure criteria. This reduction of GSI was based on assumption by Hoek-Brown (1997) that rock-drilled shaft interface were similar with recently blasted faces, therefore, GSI were reduced much as 10 points lower corresponding to one-category downgrading of rock surface quality

FHWA (1999) equation considered the presence and condition of discontinuities like spacing and aperture. However, FHWA (Brown et al., 2010) mentioned that highly fractured rock describes a rock mass intersected by multiple sets of intersecting joints such that the strength is controlled by the overall mass response and not by failure along pre-existing structural discontinuities. Also, GSI provides an improved correlation for rock mass engineering properties and should be used as the basis for estimating strength parameters. Therefore, like procedure of estimation of lower-bound resistance of shaft resistance, lower-bound of base resistance are estimated by applying of UCS of rock mass.

In case of Zhang and Einstein (1998), unconfined compressive strength was only variable for base resistance. Therefore, like procedure of estimation of lower-bound resistance of shaft resistance, lower-bound of base resistance are estimated by applying of UCS of rock mass.

Also, the concept of lower-bound is physical limit to the smallest possible capacity for a deep foundation. Considering this concept, GSI for each bearing capacity equations were downgraded much as 10 points lower corresponding to one-category downgrading of rock structure in addition to rock mass strength.

\subsection{Calibration of resistance factor considering lower-bound resistance}

Using the determined lower-bound resistance, resistance factors were calibrated considering lower-bound for each resistances (shaft and base resistance) and bearing capacity equations. For each bearing capacity equations, relationship between the ratio of lower-bound to predicted capacity with reliability index and resistance factor ratio were newly drawn like Fig. 4 and Fig. 5. These figures show the example of calibration of resistance factors for Carter and Kulhawy shaft resistance equation.

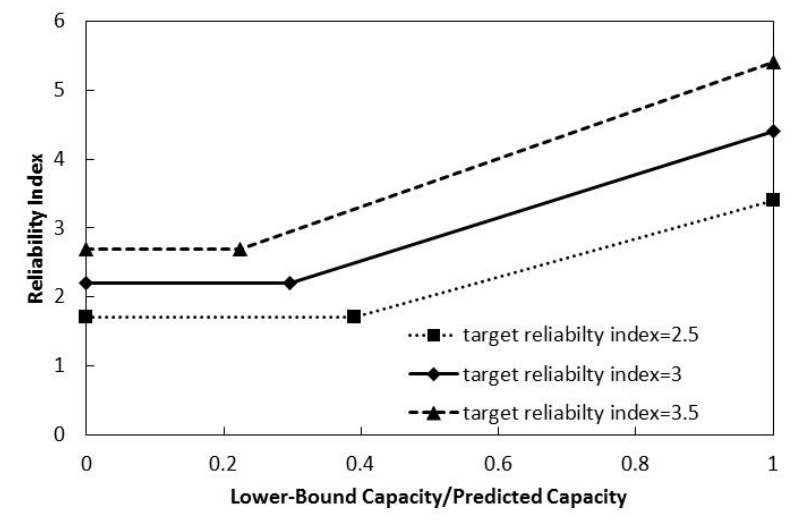

Fig. 4. lower-bound ratio with reliability index for Carter and Kulhawy (1988) shaft resistance equation

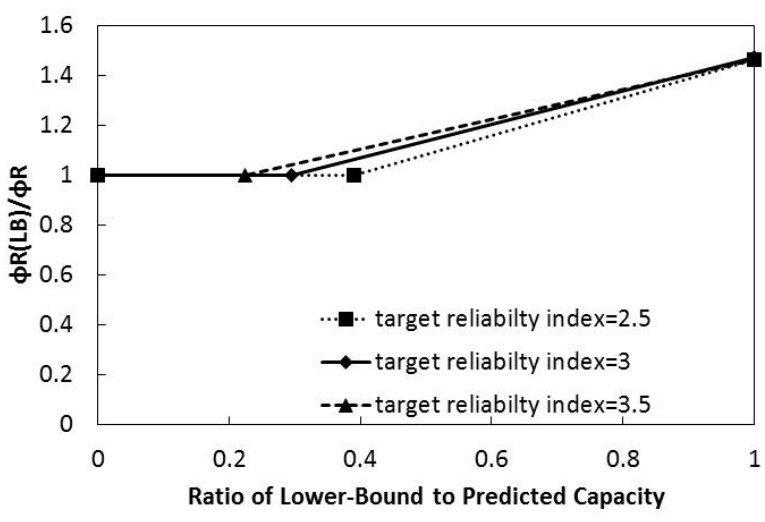

Fig. 5. lower-bound ratio with resistance factor ratio for Carter and Kulhawy (1988) shaft resistance equation

The calibration results were summarized in Table 7. As summarized in Table 7, lower-bound resistance ranged from 18 42\% of predicted resistance for shaft resistance, and 20 39\% for base resistance. Consequently, resistance factors were increased with consideration of the lower-bound resistance about $0 \sim 8 \%$ for shaft resistance factor, $0 \sim 13 \%$ for base resistance factor. 
Table 8. Summary of determined lower-bound and calibration results of resistance factors considering lower-bound resistance

\begin{tabular}{|c|c|c|c|c|c|c|c|c|}
\hline \multirow{3}{*}{\multicolumn{2}{|c|}{ Bearing capacity Equation }} & \multirow{3}{*}{$\begin{array}{l}\text { Lower-bound } \\
\text { /Predicted } \\
\text { Resistance }\end{array}$} & \multicolumn{6}{|c|}{ Resistance factor } \\
\hline & & & \multicolumn{2}{|l|}{$\beta_{\mathrm{T}}=2.5$} & \multicolumn{2}{|l|}{$\beta_{\mathrm{T}}=3.0$} & \multicolumn{2}{|l|}{$\beta_{\mathrm{T}}=3.5$} \\
\hline & & & $\begin{array}{l}\begin{array}{l}\text { Before } \\
\text { calibration }\end{array} \\
\end{array}$ & $\begin{array}{l}\text { Lower-bound } \\
\text { Calibration }\end{array}$ & $\begin{array}{l}\begin{array}{l}\text { Before } \\
\text { calibration }\end{array} \\
\end{array}$ & $\begin{array}{l}\text { Lower-bound } \\
\text { Calibration }\end{array}$ & $\begin{array}{l}\begin{array}{l}\text { Before } \\
\text { calibration }\end{array} \\
\end{array}$ & $\begin{array}{l}\text { Lower-bound } \\
\text { Calibration }\end{array}$ \\
\hline \multirow{4}{*}{$\begin{array}{l}\text { Shaft } \\
\text { resistance }\end{array}$} & Carter \& Kulhawy (1988) & $42 \%$ & 0.45 & $0.49(8 \% \uparrow)$ & 0.32 & $0.35(8 \% \uparrow)$ & 0.24 & $0.26(8 \% \uparrow)$ \\
\hline & Horvath \& Kenney (1979) & $-1)$ & 0.42 & $0.42(-)$ & 0.30 & $0.30(-)$ & 0.22 & $0.30(-)$ \\
\hline & FHWA (1999) & $20 \%$ & 0.44 & $0.44(-)$ & 0.32 & $0.32(-)$ & 0.24 & $0.24(-)$ \\
\hline & Rowe \& Armitage (1987) & $18 \%$ & 0.19 & $0.20(4 \% \uparrow)$ & 0.13 & $0.13(4 \% \uparrow)$ & 0.11 & $0.11(4 \% \uparrow)$ \\
\hline \multirow{3}{*}{$\begin{array}{l}\text { Base } \\
\text { resistance }\end{array}$} & Carter \& Kulhawy (1988) & $39 \%$ & 0.32 & $0.36(13 \% \uparrow)$ & 0.24 & $0.27(13 \% \uparrow)$ & 0.21 & $0.24(13 \% \uparrow)$ \\
\hline & FHWA (1999) & $20 \%$ & 0.25 & $0.25(1 \% \uparrow)$ & 0.19 & $0.19(1 \% \uparrow)$ & 0.17 & $0.17(1 \% \uparrow)$ \\
\hline & Zhang \& Einstein (1998) & $26 \%$ & 0.37 & $0.37(-)$ & 0.29 & $0.29(-)$ & 0.24 & $0.24(-)$ \\
\hline
\end{tabular}

1) Horvath and Kenney (1979) equation method could not determine the lower-bounds, therefore, calibration of resistance factor did not performed

\section{CONCLUSIONS}

For this study, 13 sets of load test results were collected and analyzed to determine the resistance factors. To determine the more accurate resistance factors, calibration of elastic modulus is performed and measured resistances were estimated. And then, resistance factors were determined using conventional reliability analysis method. As a results, resistance factors were determined in the range of $0.13-0.32$ for shaft resistance, $0.19-0.29$ for base resistance for the target reliability index of 3.0 (AASHTO recommended value).

After then, lower-bound resistances were calculated based on Hoek-Brown failure criteria and GSI downgrading, and resistance factor were calibrated considering lower-bound resistance. The lower-bound resistance ranged from 18 42\% of predicted resistance for shaft resistance, and 20 39\% for base resistance. Consequently, resistance factors were increased about $0 \sim 8 \%$ for shaft resistance factor, $0 \sim 13 \%$ for base resistance factor with consideration of the lower-bound resistance.

\section{REFERENCES}

1) AASHTO (2007), AASHTO LRFD Bridge Design Specifications, 4th Edition, AASHTO, Washington, DC.

2) AASHTO (2010), AASHTO LRFD Bridge Design Specifications, 5th Edition, AASHTO, Washington, DC.

3) Carter, J. P., and Kulhawy, F. H. (1988), Analysis and design of drilled shaft foundations socketed into rock, Report EL-5918, Electric Power Research Institute, Palo Alto, California

4) Fellenius, B. H. (1989), "Tangent modulus of piles determined from strain data", Foundation Engineering: Current Principles and Practices (GSP 22), ASCE, pp.500 510.

5) Horvath, R. G. and Kenney, T. C. (1979), "Shaft resistance of rock-socketed drilled piers", Drilled shaft design and construction in Florida, Department of Civil Engineering, University of Florida, Gainesville.

6) Hoek, E. and Brown, E. T. (1997), "Practical estimates of rock mass strength” International Journal of Rock Mechanics and Mining Sciences, Vol. 34, No. 8, pp. 1165-1186.

7) Hoek, E., Carranza-Torres, C., and Corkum, B. (2002), "Hoek-Brown failure criterion-2002 edition", Proceedings of NARMS-Tac, pp. 267-273.

8) Najjar, S. S. (2005), "The importance of lower-bound capacities in geotechnical reliability assessments”, Ph. D. thesis, Univ. of Texas at Austin, Austin, Tex, U.S.

9) Najjar, S. S. (2009) , "Importance of Lower-Bound Capacities in the Design of Deep Foundations", Journal of Geotechnical and Geoenvironmental Engineering, ASCE, Vol.135, No. 7, pp. 890-900

10) O’Neill, M. W., and Reese, L. C. (1999), Drilled Shafts: Construction Procedures and Design Methods, FHWA-IF-99-025, Department of Transportation, Federal Highway Administration, U.S.

11) Rowe, R. K., and Armitage, H. H. (1987), “A design method for drilled piers in soft rock”, Canadian Geotechnical Journal, CGS, Vol.24, No.1, pp. 126-142.

12) Zhang, L., and Einstein, H. H. (1998), "End bearing capacity of drilled shafts in rock", Journal of Geotechnical and Geoenvironmental Engineering, Vol.124, No.7, pp. 574-584. 